\title{
Back to the beginning: a retrospective review of the early Forums
}

\author{
Richard Shiell, MBBS Melbourne, Australia
}

What were the controversies that had the impetus to derail the Establishment and the status quo 20 years ago to result in the creation of the ISHRS and to make this new Society the driving force for the evolution of hair transplantation surgery throughout the world? We are indebted to Richard Shiell, MBBS of Australia, himself a Founding Father, and winner of the Golden Follicle and Manfred Lucas Awards, for spending many hours exploring these formative controversies as discussed in Hair Transplant Forum International under its creator and first editor, O'Tar Norwood. Ifeel confident that you will appreciate as much as I do his perspectives that are derived not only from these issues of the Forum but also from his firsthand experience: he was there in the thick of it. This is mandatory reading for anybody who considers himself/herself to be a serious student and practitioner of hair restoration surgery. His writing style makes this some of the most enjoyable reading you will ever experience. Enjoy! —W.R.

\section{Introduction}

Professor O'Tar T. Norwood is still alive and well, but retired from surgical practice. He is remembered for a lot of reasons: his friendly Oklahoma personality and willingness to teach, his early papers on Hair Transplantation, his two textbooks, and his vital contribution to the inception of the ISHRS in 1992.

His greatest contribution, however, was the establishment of his personally funded Hair Transplant Forum International, a newsletter by which the world's keenest hair surgeons could be brought together. They were able to debate points and exchange ideas, regardless of nationality or membership of any specialist field of medicine. There was no cumbersome peer review process, apart from his experienced Editorial control, so a much quicker turn-around time for ideas was possible than in the Dermatology and Plastics journals of the day, or at the triennial hair meetings. Indeed, letters and opinions were sometimes printed within a month of receipt. Without the power of the Forum, it is doubtful that the all-embracing ISHRS could have been established three years later. With these two arms, the field of Hair Transplantation bounded ahead and has never looked back.

As part of our celebration of the 20th birthday of our Society, a review of the most influential items in past Forum's has been commissioned. There have been 12 editors over those years, and each has been invited to judge what he considers to be the most important publication during his time at the helm. Here, I will review the first 3 volumes.

\section{Editorial Era of O'Tar Norwood (1990-1995)}

Volume 1 - September 1990-July 1991

The landmark issue (Vol.1, No. 1; September 1990) was a 4page invitation to subscribe, dated September 1990, and sent to all known HT surgeons of the time. It was a very incomplete list, but O'Tar had to start somewhere. The headline read, "New Publication Aims at Idea Sharing Among Surgeons," and contained a brief editorial and letters from Drs. Dow Stough, Sheldon Kabaker, and myself, Richard Shiell. It was the era of minigrafts and I wrote: "Nearly all my patients now request minigrafts and I will have to increase my numbers from 100 to 250 grafts per session to get comparable final density. This will take a lot more time."

The Forum was obviously an idea whose time had come because HT surgeons rushed to embrace it and, within 2 years, O'Tar had 400 subscribers, each paying a small sum to cover expenses. As the newsletter rapidly expanded in size and content, this subscription did not cover the cost of printing and post, and it was subsidized out of Dr. Norwood's own pocket for some time.

Although pioneers such as Dr. Bobby Limmer had already been performing microscopically dissected single-hair grafts since 1988, his bombshell paper on the subject did not make the pages of the Forum until November 1991, but more about that in the paragraphs ahead.

The early issues were full of other matters, such as the best way to prepare minigrafts, and whether they should be inserted into slits or holes, and whether they should be oriented anteriorly or laterally. Pierre Pouteaux (Paris) pointed out a very important point in the second issue (Vol.1, No. 2; November 1990): "Patients in their 50s and 60s are surprisingly happy with one or two sessions of minigrafts in the frontal area because they are seeking not so much volume as a natural aspect overall. This they can get after one single session."

Plugs and scalp reductions were still in vogue, however, although the popularity of both techniques was waning.

Much of the third issue (Vol. 1, No. 3; January 1991) was occupied with the wisdom of Dr. Emmanuel Marritt (Colorado City), a very influential practitioner who retired far too early in the mid-1990s. Manny was a confirmed user of minigrafts but pleaded the case for "micrografts" of 1-2 hairs for the front, which enabled the hair to be brushed straight back without any trick-combing over the hairline. "How many micrografts are needed? More than you originally thought!" Profound words from Dr. Marritt.

"The Donor Site" was the main topic of discussion in the fourth issue (Vol.1, No. 4; March 1991), with artwork showing the 8 methods of plug extraction then currently in use. Multi-bladed knives were appearing more frequently from inventive surgeons Vallis, Brandy, and Bisaccia. Their use was accelerated by the gradual realization that AIDS was a blood-borne condition, and that the motorized punch could be spraying an aerosol of viruscontaining blood particles around the operating room. Minoxidil also made its appearance in print in this edition with an article from Sheldon Kabaker. He stated that although strict scientific proof was still lacking, he had personally observed faster hair growth from grafts and less post-operative telogen following the use of topical minoxidil. Others confirmed these observations in Letters to the Editor, and soon minoxidil was all the rage.

In the fifth issue (Vol. 1, No. 5; May 1991), Dr. Sheldon Kabaker urged caution when using Tissue Expansion as an adjunct to flaps and scalp reductions in selected patients. In the Letters page, the use of staples was discussed and produced the same debate in 1991 as it still does today in 2012. Other closure material varied from 3-0 to 5-0 Prolene, so little has changed here in 20 years

In Volume 1's final issue (Vol. 1, No. 6; Jully 1991), HT surgical and advertising practices in the USA were compared with those in Canada, France, Mexico, Brazil, and Australia. The South American article by Marcel Gandelman surprised many with his 
Retrospective review

from page 157

account of the long history of HT in that region, dating to the early 1960s, but few surgeons persisted with the technique.

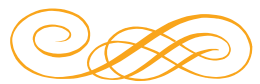

Volume 2 - September 1991-August 1992

The first issue of Volume 2 (Vol.2, No. 1; SeptemberOctober 1991) led with Manfred Lucas (Munich, Germany) stating his three important practice objectives: 1) As Fine as Possible, 2) As Many as Possible, and 3) As Fast as Possible.

Manfred was a leader in our profession and his early death was a great loss. He is commemorated with the Manfred Lucas Award, a magnificent bronze statuette, given occasionally by the ISHRS to members who have given exceptional service to our specialty

The second issue (Vol. 2, No. 2; November-December 1991), headlined "A Flap over Flaps," offered much discussion between Toby Mayer, Richard Fleming, and Danny Rousso on the subject of scalp flap surgery, which was already a technique with a declining following. The real "pearl" was buried on pages 8-9 in "Bobby Limmer Does It All, One Hair at a Time." Dr. Limmer and his assistants were dissecting grafts of 1-4 hairs from scalp strips and planting them immediately into 16 - to 18 gauge needle holes. He did not mention the term "Follicular Units," but, in retrospect, he

\section{Bob Limmer Does It All One Hair At a Time!}
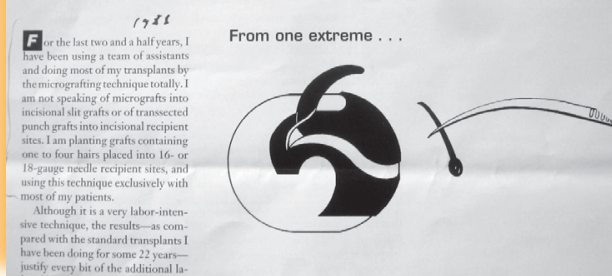

agrees that this is what he was using. His final paragraph stated: "When the hair grows in, it is impossible for the layman to discern that the patient has had a transplant. In fact I think it would be impossible for most physicians to discover it." Readers were astounded, and the technique caught on slowly but surely, with encouragement from Drs. Dow Stough and David Seager, in particular. In the same issue, it was apparent that large grafts were still the order of the day, but the debate was now between round grafts, cut by punch, versus square grafts, cut from strips produced by multi-bladed knives, and inserted into round holes.

The third issue (Vol.2, No. 3; January-February 1992) contained a report of an AAD meeting in Dallas, Texas. This was the first international hair meeting since the inception of the Forum, and it was well covered. There are reports of presentations by dermatologists Drs. Orentreich, Bluford Stough, Tom Alt, Walter Unger, Ed Griffin, Peter Goldman, and O'Tar Norwood, who made the profound statement: "The hairline of the future will probably be no hairline at all." There was also a report on the first controlled trial of minoxidil in 20 patients by Dr. Henry Roenigt, Jr. There was some agreement with my head-in-the sand comment in the previous edition that there would be a "backlash against minigrafts" due to their lack of hair density, and that plugs were still the way to go.

In the fourth edition (Vol. 2, No.4; March-Aprill 1992), it was apparent that most other surgeons at the time were still using plugs as most of this issue was dedicated to the multi-bladed knife with articles by Paul Straub and others. They used these strips to prepare square plugs or mini- and micrografts. There was also a brief report on the back-to-back hair meetings held in February 1992 by the American Academy of Facial Plastic and Reconstructive Surgery (AAFPRS) and the American Academy of Cosmetic Surgery (AACS). These were "flappers" versus "pluggers" contests that occasionally became quite heated and are remembered by many participants to this day. On page 8 was an Open Letter from Dr. Dow Stough to readers that asked them "to consider forming the International Society of Hair Transplant Surgeons." Membership was to be open to all interested medical practitioners worldwide.

The fifth issue (Vol. 2, No. 5; May-June 1992) had 4 pages on the Frechet Triple Flap technique for the correction of central slots (this had become a worldwide problem following serial scalp reductions). In addition, Henry Clamp (U.K.) wrote to say that he was in favor of the formation of an International Society.

In Volume 2's final issue (Vol. 2, No. 6; Jully-August 1992), Dr. Norwood's front page editorial declared, "We Have Evolved." Minigrafts were getting smaller and more numerous, with a report from the Moser Clinic in Austria of up to 900 minigrafts from a $14 \times 1.4 \mathrm{~cm}$ strip. The popularity of flaps and reductions was declining while mini- and micrografting were becoming the standard method of hair replacement. The use of dilators as aids for mini- and micrografting was heavily supported by many authorities. Meanwhile, Dominic Brandy reported seeing many patients discontented with the scant results of minigraft sessions performed elsewhere. He recommended a change from fee-per-graft to a feeper-session approach, and more honesty in patient pre-operative information. In the same issue, Dr. Bill Rassman condemned the practice of "lowballing" sales techniques, which underestimated the patient's present and future hair transplant requirements.

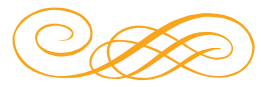

\section{Volume 3 • September 1992-December 1993}

"It Happened in Rio" was the headline of the first issue of Volume 3 (Vol. 3, No. 1; September-November 1992). This unique meeting, held in Rio de Janeiro in October 1992, was privately sponsored by Rio plastic surgeon Wagner de Morares, who had invited and paid the expenses of a number of the most highly regarded hair surgeons from around the world. We were worked hard, many of us were asked to present several papers and perform operations, but the camaraderie and social program were outstanding.

The program was so memorable that I cannot do it justice in this review and recommend that readers consult the original Forum. Some of my highlights were:

1. Simultaneous translation of papers and questions into Portugese.

2. The revelation from the Moser Clinic that they were regularly performing small 1,000 grafts in 4-hour sessions. Although a somewhat similar technique had been advocated by plastic surgeon Dr.Carlos Uebel of Brazil a full decade earlier, in Birmingham, Alabama, it was the more sophisticated technique and professional presentation from the lovely Claudia Prawetz that "kick-started" the technique of "megasessions" in North America. Indeed it started a travel procession to Vienna during 1993-1994 to see the Moser team in action. We made up to Dr. Uebel for the oversight of his earlier pioneer work with a Platinum Follicle Award in 2000.

3. The torrential bleeding we experienced in the overheated operating room. By the 2nd day we were all using "superjuice" with 1:30,000 adrenaline in our lidocaine. 
4. The shapely girls of Ipanema Beach.

This memorable meeting paved the way for the foundation of the ISHRS the following May.

"First Meeting of the Hair Surgeons International Society" was Dr. Dowling Stough's lead article in the year's second issue (Vol. 3, No. 2; November 1992 -February 1993). He proposed a 3-day global assembly of HT surgeons at the Grand Kempinski Hotel in Dallas, Texas. The aim was to establish an International Society with a primary goal of education and the exchange of ideas in hair surgery. Apart from Dr. Stough, the other driving forces behind this meeting were Drs. O'Tar Norwood, Sheldon Kabaker, and Dan Rousso.

In this same issue, Dr. Stough threw his considerable influence behind the growing concept of single-hair grafting for the production of Norwood's suggested "no hairline" hairline. Drs. Bill Rassman and Marc Pomerantz wrote of the importance of assessing the density of donor hair and had devised a small, easy to use Densitometer to achieve this. They outlined the reasons why hair density measurement should be a part of every HT patient's assessment.

An interesting note from Dr. Bob Limmer proclaimed that while studying the survival of micrografts he was astonished to find that, after 3 months, those grafts planted 24-48 hours after harvesting were sprouting earlier than those planted after 2, 3, $6, \& 8$ hours. To my knowledge this observation has not been followed up.

Not every new idea in hair transplantation makes it to the finish line and a 2-page article by Dr. Carl Shory on the advantages of the Surgitron-a High Frequency Radio Wave "scalpel"-created little interest at the time and disappeared within a year or two from the instrument sales tables. It appeared to work well, but multi-blade knives with spacers were too well established by this time. In the same vogue, a proposal to stabilize grafts in the scalp by coating them with the cyano-acrylate adhesive was revived by Drs. Robert Elliot and Robert True. This technique was first proposed by Ian Morrison of the U.K. a decade earlier, but was soon abandoned on both occasions. It was slow to apply and formed a hard crust over the grafts and it was particularly tricky when working amongst long hair from a previous session.

A quote from author Victor Hugo headlined the third issue (Vol. 3, No. 3; March-May 1993): "Nothing is so Powerful as an Idea Whose Time Has Come." This concept was powerfully demonstrated at the Dallas International Meeting (April 30May 2, 1993). At the time, this largest-ever gathering of hair surgeons had 430 attendees, almost one-third of whom came from 17 countries outside the USA. At a business meeting before the scientific program, a Board of Governors of a new society to be called the International Society of Hair and Scalp Surgery was established, and Dr. Stough was elected president by a unanimous vote. The Society was officially incorporated as the International Society of Hair Surgeons. (After further, sometimes animated debate, the name of the new organization was changed to the International Society of Hair Restoration Surgery.) The $\$ 225$ annual membership fee included the cost of subscriptions to the Forum and to the Journal of Dermatologic Surgery \& Oncology.
Dr. Patrick Frechet introduced his ingenious Scalp Extender, which seemed a great invention, but with the declining popularity of scalp reductions it had, like his Triple Flap, probably arrived too late for general adoption by the hair surgeons of the world. The following year he was presented with our first Golden Follicle Award for his many contributions.

Korean doctor Y.C. Choi stunned the gathering with his syringe-like device to aid in the insertion of micrografts. The grafts had to be inserted into a batch of the devices by deft assistants, and then the grafts were "injected" by the operating surgeon. Despite its widespread later adoption in Asia and Greece, and later modifications by Korean dermatologists Jung Chul Kim and Sungjoo Hwang, it was not embraced in the Western world. One limiting factor for the West was Dr. Choi's plan to franchise the use of the instrument and receive a share of the surgeon's turnover.

The program was packed with other interesting research material including that of Korean immunologist Prof. Jung Chul Kim on hair regrowth after bulb removal and the site of the mesenchymal stem cells. (The following year Prof. Kim received our very first Platinum Follicle Award for his work.)

Dr. Masumi Inaba presented his work on the role of the

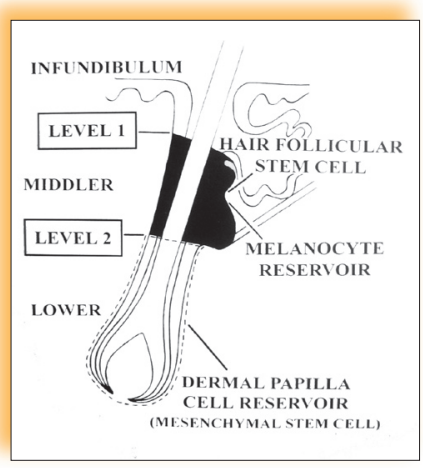
sebaceous gland and a fatty diet in androgenetic alopecia. (His belief that the stem cells resided in a zone near the insertion of the erector pili muscle had not been verified by radioactive isotope labeling.)

The enthusiasm of the issue was dampened by the announcement of the death of Dr. Norwood's wife and muse, Mary Ann, from cancer on December 4, 1992. She had been a powerful influence in O'Tar's life and career and was loved by all who knew her.

"Trouble in Paradise" headlined the fourth issue (Vol. 3, No. 4; June-August 1993), which was in reference to expressions of disappointment from many recipients of pure mini- and micrograft procedures. This author, Dr. Richard Shiell, noted that the complaints fell into four groups: 1) transplant is not thick enough, 2) transplant does not look natural enough; 3 ) there is faster fallout of the patient's residual hair, and 4) the patient's desire to have transplants removed. I also noted that all of these problems were related to the procedure being "oversold" as a panacea for the problems of old plug grafts, and that many patients expecting perfection were being drawn into the operation lists. All were correctable with further small-graft procedures, but I warned of the dangers of operating on patients with unrealistic expectations. Also in this issue, Dr. Norwood warned of the dangers of misleading advertising, a problem that remains with us 20 years later.

An article by Canadian surgeon Dr. Martin Unger demonstrated how hyperfibrotic transplants show up as a ridge of thickened tissue along the frontal hairline where grafting has been densest. This was supported by letters from Drs. Norwood, Kabaker, Puig, and Pomerantz who had all seen similar examples, and who agreed that it occurred as an abnormal fibrotic response in perhaps 1 patient per 2,000. Treatment depended on the patient's desire for correction and varied from entire block removal or debridement of the underlying fibrotic tissue to intradermal injections with $\Rightarrow$ page 160 
Retrospective review

$\checkmark$ from page 159

long-acting steroid Depot-Medrol.

After repeatedly being told that he was unsuited for HT surgery, Dr. David Seager underwent a frontal forelock procedure from friend and colleague Dr. Arturo Sandoval in

Mexico. The photographic result on his type VII baldness was outstanding and showed that, in careful hands, most patients with good donor fringe could benefit from transplant surgery. He had follow-up procedures from other friends in the years ahead and the difference it made to his appearance and personality was astounding. An article from Dr. Limmer in the following month confirmed this approach. What neither author stated was how difficult it was to get a patient to agree to this very logical approach. In 40 years, I only managed it twice. Patients seem to prefer "all or nothing" when it comes to hair replacement.

"Male Pattern Baldness is Progressive." Nothing new here you say, but in this fifth issue (Vol. 3, No. 5; September-October 1993), and particularly with an expanding Society and the pernicious influence of "miracle cure" advertising, the concept had to be reinforced. Who better to do it than Drs. Norwood, Walter Unger, Paul Straub, Richard Shiell, and Emanuel Marritt, all of whom had been operating on scalps for close to a quarter century.

The original Hamilton-Norwood charts were brought out, and O'Tar confessed that he thought that his chart was conservative and that baldness progressed with age even more than he had shown. The old hairdressers adages that "if you kept your hair until 40 then you would have hair for life" and that "baldness didn't get any worse after 60" were debunked, and it was agreed that loss continued until death. On the other hand, it was acknowledged that with graying of the hair and a decrease in obsession, many men learned to accept baldness or to be happy with their earlier transplant. The important design challenge was to make allowance for future progress. A few transplants front and back was NOT a satisfactory long-term solution. A high hairline and avoidance of crown grafting in young men were considered wise design plans.

Dr. Manfred Lucas, an artist and surgeon from Munich, Germany, pointed out that Leonardo da Vinci's so-called facial "Rule of Thirds" only applies to children and females and it is rare to find any adult male with this hair distribution. In planning a male hairline, we need to make the frontal point at least $2 \mathrm{~cm}$ higher than this point.

"Scalp Reductions; Are They Necessary?" Headlining the volume's final issue (Vol. 3, No. 6; November-December 1993) were Dr. Norwood's courageous, fighting words. Despite the warnings by Drs. Norwood, Morrison, and Shiell as early as 1983, in their paper "Complications of Scalp Reductions," the technique had gathered pace over the subsequent decade. Many surgeons were performing wider reductions with the use of extensive undermining, with and without the aid of Tissue Expanders and Tissue Extenders. The simple rationale was to get rid of baldness but, as Dr. Marritt reminded us, "There is no such thing as a free lunch," and the trade-off was a redistribution of the good hair with raised and thinned side hair, altered hair direction, stretched and thinned scalp tissue on top, and a scar that was difficult to conceal with styling. All this occurred at a time when baldness was progressing relentlessly in the stretched scalp.

These were all the sequelae of scalp reduction repeated to the point of closure-hair to hair. If alopecia reduction had been practiced conservatively, as advocated by the originators, Canadians Guy Blanchard and Martin Unger, then these problems would never have arisen. Unfortunately, patients and doctors got carried away in the excitement of seeing top baldness disappear and the eventual result was the gradual discrediting of an entire range of surgical procedures. This was well in the future, however, and the debate raged on, as the following editions of the Forum will show. Many surgeons leapt to the defense of their favorite procedure, and one surgeon even stated at a subsequent meeting that it could be deemed "malpractice" NOT to offer the option of alopecia reduction to a suitable patient. The procedure gradually became less popular, however, but today is still practiced on select patients by a small number of experienced practitioners.

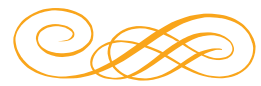

\section{Volume 4 • January 1994-December 1994}

Headlining the first issue of 1994 (Vol. 4, No. 1; JanuaryFebruary 1994) was "The Gathering Storm," which referred to the expected vigorous response to the attack on scalp reduction procedures in the previous issues.

Dr. Mario Marzola (Adelaide, Australia) led off with the opening volley: "It is inconceivable that anyone should suggest that scalp reductions are not and should not be legitimate treatment for Male Pattern Baldness. What can be suggested is that in some surgeon's hands, scalp reductions have not produced the results they expected."

Dr. Dominick Brandy (Pittsburgh, Pennsylvania, USA): "Simply because there are aesthetic challenges with alopecia reducing procedures doesn't mean that we should abandon this extremely viable tool."

Dr. Gerard Seery (Sacramento, California, USA): "I was astonished at the onslaught on Scalp Reduction in recent editions and hope that the opinions expressed by your contributors do not represent the feelings of hair restoration practitioners in general."

Dr. Carlos Puig (Twin Lakes, Wisconsin, USA): "Logic dictates that making the bald area as small as possible prior to relocation of grafts will result in conservative use of the available donor area and an enhanced result.... Alopecia reductions are a valuable tool incorporated into many of our patient's treatment plans."

Dr. Walter Unger (Toronto, Canada): "It is important to note the differences between negative effects that are avoidable and those that are not avoidable.... Repeated A.R.s will cause some thinning of donor hair but donor site harvesting with suturing does so too.... We should not deny our patients the benefit of A.R. because of the mistakes of a few physicians who attempt too much in the wrong individuals."

Meanwhile, AR received further support with the trials of Frechet's silastic Scalp Extender device already underway in various parts of the world and a new design being trialed in France. On the other hand, there was continuing opposition to AR, as noted by Dr. Pierre Pouteaux (Paris, France): "I am not 
enthusiastic with scalp reductions, especially on the vertex where the alopecia is diffuse." The unrelenting, continuous hair loss constituted a major objection to AR since, in even the most expert hands, the AR scars and altered hair direction would eventually become apparent

Other important points were made in this issue. Dr. Paul Straub pointed out that, although hair loss is continuous in men with pattern baldness, "the rate of hair loss usually diminished with later age." He added that it was not the rate of hair loss that was important, however, but the appearance of baldness, which could suddenly become evident after decades of gradual loss.

Dr. Scott Friedman noted that the work of Prof J.C. Kim on follicular transection paved the way for future hair cloning. Under ideal conditions, with transection at the correct level, one hair could produce two viable grafts. Dr. James Arnold commented: "What is of practical value at this time is the knowledge that a follicle that is missing the lower bulb will probably still grow a new hair." In the fuss over the importance of microscopic dissection that arose in future years, this important point was usually forgotten.

The Great Debate on AR continued in the year's second issue (Vol.4, No. 2; March-Aprill 1994). Dr. Guy Blanchard, the co-developer of AR, wrote: "Scalp reductions were originally designed to address the problems of grades III, IV \& V baldness in middle-aged men but it seems to have evolved into a catch-all procedure... Scalp Reduction may be worked once, perhaps twice, rarely more, into a set hair transplantation program.... The key is, don't overdo it."

Dr. Sheldon Kabaker agreed: "It should be emphasized that, if scalp reduction is proposed to a patient, it should be to lessen the bald mid-scalp and crown and not to totally remove the bald area." On the other hand, in a response to a statement Dr. Marzola made in Vol. 3, No. 6, Dr. Kabaker predicted that scalp flaps were not "dead" but "will have their new heyday with the advances we now have using tissue expansion." Bilateral and triple advancement transposition flaps devised by Richard Anderson, which could achieve coverage in as short a period as 90 days, were on their way.

In relation to the continuing vigorous debate between "pluggers, flappers, and shrinkers," the wise and experienced Dr. Bobby Limmer pleaded, "There is no need for these camps to be at war-the goal is what is best for the patient, not for the surgeon."

The equally sage Dr. Norwood drew attention to what was becoming increasingly obvious to many "old-timers" in our profession: that hair transplants were not "permanent" as claimed in most of our literature and across the consulting desk: "I have noticed in my own transplant (first started some 25 years earlier) that there has been considerable thinning over the years. I have continued to add transplants so the thinning has not been as obvious.... Like all aging processes this may occurfaster in some people than in others." This author (R.S.) saw Dr. Norwood in early 2012, 18 years after he wrote the above lines and I am pleased to report that the 84-year-old O'Tar is still as wiry and bright as ever, even if his hair is a little greyer and sparser.

Other debates continued on the merits of holes vs. slits in the recipient site and single-blade vs. multi-blade knife.

The excellent meeting of the March 1994 American Academy of Facial Plastic and Reconstructive Surgery in Birmingham, Alabama, was reported on very fully. This was one of the last times that non-members were invited to participate, and henceforth the two organizations went their separate ways. This was a tragedy in some respects, because we lost great luminaries such as Blu Stough, Tom Alt, Sam Ayres, Ken Buchwach, Dick Webster, and Gary Monheit who never joined the ranks of the ISHRS.

The rarely mentioned problem of malpractice suits after hair and scalp surgery was discussed in Birmingham by Dr. Kabaker. From his experience as an expert witness in some 20 cases, he said that most suits were dropped or settled out of court and only around $10 \%$ went to trial. In these cases, the jury was usually unsympathetic with the plaintiff and favored the defendant doctor. (This author [RS] agrees with these figures from my 40 years' experience as an expert witness on hair surgery cases in Australia. The expert attorneys usually know which cases can be defended and which must be settled.)

The third issue of 1994 (Vol. 4, No. 3; May-June 1994) noted the beginning of the Mega-session Era and the inevitable debates that would follow regarding the wisdom or foolhardiness of such seemingly ambitious undertakings.

Dr. Victor Loria (New York) led off with 1,000 grafts to the hairline region alone using a 16-gauge Nokor needle for the recipient sites, and Dr. Bill Rassman countered with 2,250 grafts to the full scalp. Dr. Loria's grafts were graded and placed in slits or $0.75 \mathrm{~mm}$ holes as close as $1 \mathrm{~mm}$ apart. There was no mention of microscopes but 2-3 power head loupes were commonly employed at this time. The importance of teamwork was emphasized. Dr. Rassman employed 6-9 assistants for cutting grafts and 2-4 for planting, noting that staff fatigue was a major problem with mega-session work.

Dr. Dow Stough wrote an excellent paper warning of our increasing legal obligations in the age of minigrafts and megasessions. There was increasing necessity for valid Informed Consent documentation, which should include acknowledgment by the patient that he had actually read and understood the preand post-operative material provided. Pre-operative photography was mandatory, as was documentation of previous hair surgery done elsewhere. Realistic goals should be set and low hairlines discouraged, while giving an estimate of the likely costs involved.

Just when we thought we had enough variables to consider along came a paper from Dr. Walter Unger describing his experiences with the Ultrapulse $\mathrm{CO} 2$ Laser to create slits in the recipient area. He had been gradually increasing the number of slits per case and had studied the 4-month results. At the time of his writing, he was up to 150 slits to the right vertex and compared them with 150 slits made with a scalpel blade. He had the impression that there was less graft compression but, on the other hand, that there was some destruction of residual vellus hair and more persistent crusting. He urged caution whilst this modality underwent further trials.

No such caution was evident in Europe where, after brief observation in Toronto, there was a rush to acquire laser machines and Laser Hair Surgery was dominating the advertising. Within 12 months, if you were not using a laser, your practice was next to dead.

Meanwhile, Dr. Richard Anderson released details of his Expanded BAT and TAT Flaps for MPB. These were ambitious random advancement and transposition flaps combined with the use of tissue expanders, and for the experienced surgeon. Instructional videos were available, and there was some brief interest from the Plastic Surgeons within our group, but the day of the flap for restoration of MPB had passed.

"Female Androgenetic Baldness" was the topic for a long paper by Dr. Norwood in which, he said it was quite different

$\Rightarrow$ page 162 
Retrospective review

from page 161

than the baldness commonly seen in men. The hairline was frequently spared, and there was diffuse thinning on top of the head and often at the sides as well. It did not usually seem to be related to raised androgen levels but rather was frequently associated with Polycystic Ovary Syndrome. It appeared to be a result of increased hair follicle sensitivity to existing androgens. A questionnaire sent to prominent hair surgeons produced the following interesting and very varied responses (in summary):

- Dr. Marritt, like Dr. Norwood, did not like operating on women. They both felt that there was a lot of telogen effluvium and results were poor.

- Dr. William Coleman III (Louisiana) was happy to treat women patients with minoxidil, topical estrogens, and occasionally spironolactone. He used transplants for hairline reconstruction after facelift procedures but had the impression that females were looking for a thick head of hair and were frequently dissatisfied with the results.

- Dr. Marcelo Gandelman (Brazil), on the other hand, used minigrafts into slits along with topical minoxidil and felt that women made better patients than men. He saw a lot of telogen loss but had warned his female patients of this in advance and generally found it to be only a temporary inconvenience.

- Dr. Manfred Lucas (Germany) reported on over 40 women with androgenetic alopecia. He used micrografts of 2-3 hairs into carefully positioned micro-slits, and, although there was some loss of non-transplanted hair, he felt that most of his female patients were very satisfied with their results.

- Dr. Dow Stough operated only when there was significant hair loss in the recipient zone and good remaining donor hair of at least 20 per $4 \mathrm{~mm}$ field. He felt women with diffuse alopecia involving the donor zone should be avoided. He noted that minoxidil was helpful but had found post-op telogen to be so frequent that he told his patients to expect it. He rejected some 95\% of female patients with androgenetic alopecia as unsuitable for surgery but noted that the remaining 5\% did well.

- Dr. Pierre Pouteaux (Paris) was more optimistic and operated on all who had adequate donor site, but he very frequently did test grafts of 60-80 minis. He claimed never to have seen telogen effluvium.

" $H$ " Factor or " $X$ " Factor? After elimination of obvious causes of poor results following hair transplantation, an " $\mathrm{X}$ " or unknown cause was proposed by Norwood \& Shiell in their 1984 textbook. They suggested that it might occur in perhaps $1 \%$ of cases of poor results.

Joseph Greco (Venice, Florida) proposed an "H" or "Human" factor as the cause of many poor results. He suggested that improper handling of the grafts during all phases of the operation could result in poor growth. He felt that grafts should not be overhandled and should be kept well hydrated. Sharp instruments were essential so a firm but soft cutting surface that did not rapidly damage blades was mandatory. Staff fatigue or a cavalier attitude to graft handling were other contributors to the " $\mathrm{H}$ " factor.

Note: By definition most of these factors would be ruled out with "X" factor as it should only be so labeled after the doctor, very conscious of the earlier problem, has attempted to eliminate any " $\mathrm{H}$ " factors. Certainly more causes have been found for "poor growth" in grafts over the years, but the tiny percentage of "X" factor remains.
In the fourth issue (Vol. 4, No. 4; Jully-August 1994), the editor reported on a visit to the office of the multi-talented Dr. Bill Rassman in Los Angeles where they were regularly performing sessions of over 2,000 minigrafts cut from multi-blade strips. Difficulties included quality control of grafts and planting with up to 12 assistants working on one patient. Long sessions and staff fatigue, along with the need for additional anaesthesia and vasoconstriction, were the major problems encountered. The reward was a natural growth of sparse hair, and the need for "dense-packing" of grafts at the hairline was emphasized.

Dr. Rassman wrote about the need for quality control and the restriction of unscrupulous advertising. He also reported on the first cases of scalp necrosis resulting from closely spaced holes at the recipient site created by the new $\mathrm{CO} 2$ laser. We would hear much more about this problem in the years ahead until lasers eventually faded from the HT scene.

Dr. Dow Stough predicted the demise of the large round graft: "The final judge andjury will side with the technique that best imitates Mother Nature.... The arguments will continue but surely a trend has developed. The large round graft appears to be a dying breed."

Dr. Loria recanted earlier

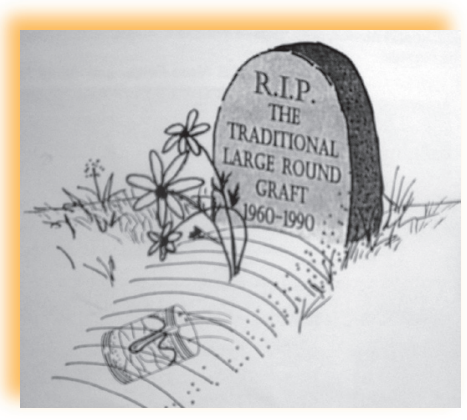
statements and was now reverting to larger grafts behind the micro-grafted hairline. This was to be a common stance until FUT eventually reigned supreme after some years of debate.

There was a long article, "Dissatisfaction and Litigation after Hair Transplantation," and some summaries of four legal cases that had reached court in Australia. This author (RS) emphasized that although legal suits were rare, there was actually a good deal of dissatisfaction amongst patients (perhaps 2\%), which was usually as a result of what the patient considered to be a failure to receive what was promised by the operative surgeon. A sympathetic approach to the dissatisfied patient was urged, along with a willingness to perform additional procedures free of charge. Time was an important factor in addition to being seen to be doing something. With the passage of time and some additional hair, many unhappy patients could be turned around without redress to litigation. I warned about operating on patients with any sign of Body Dysmorphic Syndrome, which is not always easy to differentiate from the commonly seen, obsessive regular hair-loss patient.

The fifth issue (Vol.4, No. 5; September-October 1994) was dedicated to "The Big One," the ISHRS annual meeting held in Toronto, while Dr. Paul Straub was president. It was a huge meeting with lots of presentations, but there were also mistakes made because of the unexpectedly high attendance. Important lessons were learned by the ISHRS Board and Administration.

Mega-sessions and multi-blade knives dominated the program and corridor chat (and the author watched Dr. Bill Rassman pass 3,000 grafts in a procedure, the day after the Toronto meeting). Dr. Rassman emphasized that the trick was to dissect out the pilo-sebacious unit of 1-4 hairs (later termed "Follicular Units") and plant them into very small slits.

Dr. Bobby Limmer warned of the dangers of over-selling the technique because, in his experience, even 8,000 small grafts did not create the appearance of a full head of hair on a large bald scalp. 
Dr. Dow Stough presented a translation of a 1943 paper that had been published in the Japanese Journal of Dermatology 50 years earlier by Dr. Tamura. Although Dr. Tamura did not operate on bald scalps, he had the ability to replace eyebrow, axillary, and pubic hair with similar small units. We wondered how the history of hair transplantation in the West would have differed if this war-time publication had filtered through to us 3-4 decades earlier.

Dr. David Whiting presented the subject of the use of oral finasteride, a 5 alpha-reductase inhibitor, in MPB. The incidence and severity of side effects appeared to be low, and we learned that many doctors attending the meeting were already using the medication. Dr. Bessam Farjo (United Kingdom) wrote that he had obtained excellent results using a combination of topical minoxidil and oral finasteride.

Mechanized HT was as much a point of discussion in 1994 as it is today 19 years later with many of the same contenders-viz the Korean implanters of Dr. J.C. Kim, the French Calvatron apparatus by Dr. Pascal Boudjema, and another from Dr. Pierre Bouhanna. It was stated that time would settle the matter, but it is certainly taking longer than any of us expected.

The controversy over the merits of scalp reductions continued unabated, and Dr. Frechet presented a Scalp Extender that utilized the principle of "scalp creep." Two other devices, the Sure Closure and Star Device, were also presented, but they had only a small following compared to the Extender. Dr. Rassman wrote that he regretted his own three crown reductions, and that his impression was that he had experienced accelerated hair loss as a result of the procedures.

The Nido Corporation of Japan presented several papers on Artificial Hair. They wished to dissociate themselves from the artificial hairs that had seen the procedure banned in North America in 1984. Their type of fibre had never been marketed in the USA. Dr. Shiro Yamada was happy to allow inspection of his own fine head of implanted artificial hair, and he noted that the infection rate of about $2 \%$ compared quite favorably with minigrafts. There were other problems that were not, however, so easily brushed aside. These were fibre breakage and sebum build-up around the base of each fibre, and, most important of all, the annual loss of implanted fibres from the scalp, which could be as high as $30 \%$ per year. It was an alternative to a hairpiece, however, for those with inadequate quality or quantity of donor hair.

"Lasers-Help or Hype?" was the header of Dr. David Seager's lead article in the year's final issue (Vol. 4, No. 6; November-December 1994), although earlier in the year Dr. Walter Unger had already written about his continuing cautious experience with the scalp laser. Using a Coherent Ultrapulse 5000 laser and a Sharplan laser, Dr. Seager pointed out the advantages of an almost bloodless field and the great ease of planting grafts into the vaporized slit-shaped defect.

The disadvantages were the tremendous cost of the machine and the likelihood of it becoming quickly obsolete with the rapid progress of technology. The machine was currently slower than making slits by hand, and there was some concern that making slits for a second or third session of grafts might be problematic.

Dr. Malte Villnow (Germany) claimed to have harvested and planted up to 2,300 grafts in 4 hours with 8 assistants using the Sharplan Silktouch 40 Watt laser. (Some doubt was later expressed about whether all these slits were made with the laser or some with a blade.)
Claudia Moser said that the Moser Clinic of Vienna had used two types of laser, the Coherent 5000 and the Surgilase 150XJ, for 8 months and had found no significant difference between the two, but warned of possible dangers from the low energy Sharplan laser. They did not intend to increase hole numbers past 500 until there was a proper scientific evaluation of results. They always compared results with conventionally made graft sites on the contralateral side, and reported prolonged healing and redness in the laser sites.

Dr. Martin Unger went to bat for the beleaguered cause of scalp reduction and made the valid point that the faults did not lie with the AR procedure but with the choice of patient and with the amplitude and number of procedures performed on each patient. A quick survey in the room at Toronto showed that over $90 \%$ of surgeons were still using AR in their practice so "in spite of the bashing it was receiving from a vocal minority, the procedure was still alive and well."

Dr. Gerard Seery gave some tips on avoiding the commonly observed problems with AR and finished with the wise words: "It is time we stopped blaming the operation for our own surgical shortcomings."

This author (RS) was concerned "that there was far too much pressure to achieve ever-larger sessions with ever-smaller grafts without any serious attempt to assay the results." I asked: "Are the results of a 2nd session of 2,000 grafts as good as the first?" I wondered if "it is possible that a patient could lose 500 grafts without either doctor or patient being any the wiser." I also called for a moratorium on mega-graft numbers while we assessed the results scientifically.

To conclude the issue, Dr. Norwood made an interesting plea for patient welfare, noting: "I have had hair transplant operations over the past 25 years, with and without pre-medication... there is a tremendous difference... to do hair transplants in this day and time without pre-medication is barbaric."

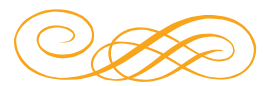

\section{Volume 5 - January 1995-December 1995}

"The Frontal Forelock" was the 1995's lead article (Vol. 5, No. 1; January-February 1995). It was not a new concept, but Dr. Michael Beehner eloquently made the case for a more limited transplant in extensive baldness. He had used it in 27 patients up to that date, with the majority receiving an isolated island of mixedsize grafts with large minigrafts in $2 \mathrm{~mm}$ holes in the centre and a surrounding zone of small mini- and micrografts. Dr. Beehner recommended it as an approach for the "very young patient" with a large area of potential baldness and for the "very bald" where there was limited remaining donor hair. The procedure was generally done in three sessions with a spacing of four months between procedures and could be done with or without scalp reductions.

Dr. Beehner pointed out that this approach re-created a natural pattern frequently seen in men where most of the top hair had gone leaving a frontal forelock. An alternative to this approach was to connect the denser forelock to the lateral fringe by a number of natural looking micrografts.

A similar system was advocated by Dr. Bernard Nusbaum at the January 1995 ASHRS meeting in Los Angeles. Unlike Dr. Beehner, Dr. Nusbaum recommended a concave posterior edge to the forelock so that a natural circular bald patch remained on the crown.

Several countries already had national hair transplant societies. The American Society of Hair Restoration Surgery

$\Rightarrow$ page 164 
Retrospective review

from page 163

(ASHRS) held its first meeting in January 1995 with Dr. Martin Unger (Toronto) elected Chairman. The 3-day meeting was well organized and there were some memorable moments, such as when Dr. Anthony Pignataro described a method of attaching a hairpiece to a series of small prostheses screwed into the skull (like dental implants). At the end of his presentation he unclipped the hairpiece on his own head with a deft hand and invited audience members for a closer look in an adjacent hall. To the chagrin of the session chairman, an estimated $25 \%$ of the audience promptly departed to view this marvel of medical technology. (In retrospect, it did not "catch on.")

Dr. Walter Unger noted that after two years of research with lasers he had concluded that there was a more "natural result" with grafts inserted into laser-created slits. Approximately $1 \%$ of patients had unexplained "poor growth." Audience members complained that convincing photographs of mega-sessions and laser transplants were still lacking.

Manfred Lucas (Germany) wrote of seeing "Trouble with Mega-sessions" performed in other offices in Germany, where the rush to perform ever-larger graft sessions had resulted in difficulty in donor closure and wide, unsightly scars. He had also observed cases of scalp necrosis in the middle of the recipient area, presumably due to the very close spacing. These problems would continue in the rush of inexperienced transplant surgeons to join the "Megasession Club."

Similar sentiments were expressed by Dr. Gary Hitzig, who was alarmed at the rush to megasessions of small grafts, saying: "It takes 1-2 years to truly evaluate your work and 10-20 years to know all the consequences.... The advent of large sessions of small grafts has been pioneered primarily by physicians who have only recently come into the field...."

"A Blast Heard Around the World" was Dr. Norwood's headline of the year's second issue (Vol. 5, No. 2; March-April 1995) after the Oklahoma bomber left a permanent scar on his home city. He hoped that "this example of man's ultimate inhumanity to man may in the long run make the world a better place." (This author [RS] is writing this in the last week of July 2012, with the tears of the world still flowing from the recent Colorado cinema massacre. It seems that little has changed in 17 years.)

This issue was devoted mostly to megasessions and laser surgery. After inspecting the laser in action, Dr. Norwood put his cards on the table in his editorial: "The laser is a machine that burns a hole in the skin. There is something about the way grafts fit into these dry, hard laser holes that I don't like...no matter how much technology improves... you are still creating heat, sealing blood vessels, and damaging tissue. I believe that it will never equal cold steel for yield."

On the other hand, Dr. Walter Unger was optimistic in a following article (complete with long-awaited photographs). He admitted that blood vessels were being sealed and advised caution for the present. Some machines caused more thermal damage to adjacent scalp and close spacing should be avoided until more data was available. He reiterated his former belief that, in his hands, well-spaced laser slits gave a more natural and less-compressed result compared with conventional round or slit grafting.

He apologized for his $2 \frac{1}{2}$-year delay in releasing his results, but added: "I nurture the increasingly quaint and old fashioned idea that new technology should be investigated slowly and cautiously." He warned of the risks of commercial exploitation of this powerful new tool by relative novices. Dr. William Beeson, with just over a year of laser experience, expressed similar views. With the wide range of machines available and the variability of settings, he lamented the difficulty of "comparing oranges with oranges."

Dr. Malte Villnow (Dusseldorf, Germany) also urged "extreme caution," but this caution was not at all evident from a reading of his paper. First commencing laser surgery in January 1994, he claimed to have performed over 300 procedures and 100 megasessions with the Sharplan Flashscanner by November of the same year. This included one procedure of 2,500 grafts. He claimed that by using the new machine he could now make holes $30 \%$ faster than with conventional techniques. No bandage was necessary after surgery and the results were more natural in appearance. His photographs were impressive but their authenticity was later challenged.

On the other hand, fellow German Dr. Karl-Heinz Wagner (Augsburg) wrote of seeing cases of irreversible thermal scalp damage caused by laser megasessions and urged greater caution. Authors from the Moser Clinic (Vienna, Austria) agreed and noted that, in their experience, healing was impaired, growth was slower, and yield was less when compared with adjacent conventional slits. They said that the only advantage of the laser appeared to be as a marketing aid.

Dr. Manfred Lucas (Munich) lamented the explosion of laser clinics "shooting up like mushrooms" in Germany and "a dramatic increase in wide and ugly occipital scars...the plundered donor areas will make it impossible to obtain the same number of transplants in the second and third sessions; but this is of no interest to many institutes."

In the USA, Dr. Marc Avram (New York City) had commenced a large controlled study of hair grafting comparing laser holes of different parameters with those made with conventional tools.

Conventional Grafting. Dr. David Seager (Toronto) urged caution with dense-packing of grafts and reported inferior growth in second session minigrafts as compared with that from the first session. He said that sessions should be at least three months apart.

Dr. Dow Stough (Hot Springs, Arkansas) sent some valuable tips including the benefits of full spectrum overhead fluorescent lighting in his O.R, oral Valium pre-medication, and Precise DS\#25 staples for donor site closure. (His conviction of the superiority of staples for both patient and surgeon is ongoing but still hotly debated to this day.) His graft sessions were generally from $400-600$ placed into holes of $0.8 \mathrm{~mm}$ to $1.25 \mathrm{~mm}$. He preferred his patients to be over 35 years old, but occasionally he operated on those as young as 25 . He was experimenting with laser surgery.

Dr. Robert Yoho (Pasadena, California) reported a disappointing result on his attempt to view a demonstration of the Medicamat Calvatron machine with Dr. Pascal Boudjema in Paris because of an apparent malfunction of both the machine and the operator. (Representatives from Medicamat responded the following month explaining that the problems had arisen due to a communication breakdown between Drs. Yoho and Boudjema, and that the machine had some 50 happy users.)

Scalp Extenders. Dr. James Vogel (Baltimore, Maryland) defended the extender from criticism by those who claimed it was just a faster way to achieve a posterior slot deformity. He said that the whole point of the Frechet Extender was to remove 
bald scalp. A central slot resulted that was then corrected by the use of a Frechet Triple Flap.

Dr. Dominick Brandy (Pittsburg, Pennsylvania) reported on what he considered to be the advantages of custom-made extenders using American materials, rather than importing the French made Frechet Extenders, which did not yet have FDA approval. The acrimonious debate fizzled out as reductions and extenders both gradually faded from mainstream hair restoration techniques.

A proposal for merger of the AACS with the ISHRS was rejected by the Board of the ISHRS.

(Vol. 5, No. 3; May-June 1995) Looking back from the year 2012, it must be difficult for readers to realize the debate that raged for several years over the subject of small grafts and the density of spacing in the recipient region. Anything larger that a double follicular unit would be regarded as unthinkable today, but in 1995 there was a wide variety of graft shapes in use as well as the sizes of recipient holes and slits. Drs. O'Tar Norwood and Marc Pomerantz both discussed these matters at some length.

Dr. Russell Knudsen (Sydney, Australia) discussed the cost benefit analysis of megasessions and pointed out that with minigrafts there was a massive increase in graft numbers and cost to plant the same number of hairs. With session numbers increasing from 1,000 to over 4,000, he makes the important point that "the history of hair transplantation is littered with good ideas that were taken to extremes before a moderate consensus emerged."

In his article "The Ultimate Question About the Laser," Dr. David Seager said that "when an experienced hair transplant surgeon starts using a laser, it's almost like starting to learn hair transplantation all over again" and that "results are not as consistently reproducible as they are with conventional methods." With two new laser machines on the horizon, he was optimistic about the future of the modality.

In discussing the relative merits of the Ultrapulse vs. Sharplan lasers, dermatologist Dr. Bob Limmer said: "At this time, the laser should, in my opinion, be regarded as a research instrument that has, unfortunately, been used too often as a tool for marketing one's practice."

Dr. Limmer, a pioneer in the use of follicular unit grafts cut with the air of a dissecting microscope, presented a most enlightening paper: "17 Reasons for Using Small Grafts." It was hard to believe that even after this factual and logical presentation it was at least another decade before everyone was following his advice, but that is often the way with scientific advances. With megasessions and microscopes, the limiting factors were staff numbers and the training and experience required to produce good, consistent results. It was no longer a procedure for the occasional operator.

In another paper, “The Ethics of Scalp Reduction," Dr. Limmer agreed that scalp reduction had a role on selected individuals but he "viewed with dismay the indiscriminate use of scalp reduction... as an integral and often initial procedure..., irrespective of the age of the patient or the extent of hair loss." His views were echoed by fellow dermatologist and pioneer hair transplanter, Dr. Jay Barnett (New York City).

This author (RS) wrote of some medico-legal cases that had come across and what could be learned from them. Common causes of litigation in hair transplant field included:

- Surgeons belittling the work of other surgeon.

- Operating on women or young men in the early stages of hair loss.

- Scalp flaps with or without associated scalp or tip necrosis.
With his "tongue in cheek" style, Dr. Russell Knudsen presented "12 Tips for New Players," which should be included amongst the classics of our profession. These included such gems as:

- Never operate on someone more obsessive than you are.

- Be an operating pessimist. They always go more bald than you expect and faster than you expect.

- In young, very bald patients, the only thing worse than saying "no" is saying "yes."

- Every surgeon is a genius at the end of an alopecia reduction. The test is whether they maintain their IQ six months after the sutures come out.

Cold Grafts: Dr. Dow Stough pointed out that in any type of transplantation all grafts or organs are kept cold, and now that operations are taking much longer, hair transplants should be no exception.

New Toys for the Boys: The Redfield Infra Red Coagulator was developed in Germany around 1980 but had more than 15 years to be introduced into the USA. With its gentle glowing light tip, it was a useful alternative to conventional electro-cautery with its associated smoke, noise, and aroma of cooked flesh. Its only negative feature was the US\$3,300 price tag.

Dr. Michael Elliot wrote of the importance of avoiding slot formation in alopecia reduction. He preferred to leave and graft a few centimeters of baldness, and was very happy with the 10-year results that he was seeing after one, two, or three reductions. He wondered what the 10-year results would be like following triple flap corrections for central slots.

(Vol. 5, No.4; Jully-August 1995) Many ISHRS members will not know that there was a time when the American Academy of Facial Plastic and Reconstructive Surgery (AAFPRS) ran very fine meetings dedicated to hair restoration surgery. There was an excellent meeting at the Drake Hotel in Chicago in June 1995 with a faculty drawn from many specialties and countries.

The first day was devoted to autograft surgery where the megasessions of Dr. Bill Rassman drew considerable attention. He had emphasized that he was now using follicular units into 18-gauge Nokor needle slits and that these have much less bulk than a small minigrafts. It is possible to insert 4,000 such units into fine slits without fear of necrosis. Dr. Walter Unger was increasingly convinced that lasers had much to offer, particularly with the newly developed automatic scanning heads. (Note: Reports of poor results coming in from around the world demonstrated that the correct employment of this technique was still far from perfect.)

The second day was devoted to flaps and scalp reductions, scalp lifts, tissue expansion, and extenders. Without any fresh facts, the topics remained as controversial as ever.

Day three opened with an outstanding presentation on practice promotion from Dr. Carlos Puig. This was followed by frank discussions between Drs. Robert Cattani, Sheldon Kabaker, Mario Marzola, Bill Rassman, and Dominick Brandy on the cost and relative merits of various types of advertising and promotion. The ethics and medico-legal issues surrounding training, marketing, fee-splitting, and our attitude to substandard work done by colleagues was also discussed. As Ingrid Wagner-Smith said in her address: "We must be scrupulous in our practice or we shall not survive. And rightly so."

The first meeting of the Italian Society of Hair Restoration Surgeons was held in Rome on June 9-10 with over 150 participants. 
(Vol. 5, No. 5; September-October 1995) The issue of deteriorating ethical standards was brought up again in President Dr. Bob Leonard's opening address at the Las Vegas meeting on September 5-8.

The usual debates over the merits of minigrafts, megasessions abounded and in response to criticism of his huge graft sessions, Dr. Rassman responded with what was the quote of the meeting: "Those who say it can't be done should not stand in the way of those who are doing it every day." To emphasize his point, Dr. Rassman bravely presented 23 live patients in various stages of completion.

There were many talks regarding the use of lasers and following the talk on the Sharplan laser from Dr. Malte Villnow of Dusseldorf, fellow German, Dr. Manfred Lucas rose to say that although Dr. Villnow admitted to no complications, he was seeing plenty of his problems in Munich, including haematomas and necrosis. Claudia Moser of Vienna further undermined Dr. Villnow's credibility by recognizing one of his slides as being that of a well-known German doctor who had received prior cold steel surgery elsewhere.

The use of the multi-blade knife was under attack as well, as Dr. Bob Limmer pointed out that even in the best hands some $15 \%$ of follicles were transected, compared with $3 \%$ when cut expertly using a single blade and magnification.

Scalp reductions received another reprieve with the announcement by Dr. Martin Unger of his new P.A.T.E. (Prolonged Acute Tissue Extension). This was claimed to permit $100 \%$ more scalp removal over 3 hours and that the extension process could be continued over the following month by inserting a Frechet Extender. Dr. Gerry Seery advocated his Anchor Scalp Reduction to minimize stretchback in mid-line reductions, and Drs. John Schwinning and Gary Hitzig suggested a Prolene Sling for posterior reductions.

Finasteride trials were underway and results were very promising. There was some concern about its effects on male libido and the potential for damage to the fetus.

Over 100 participants attended the inaugural meeting of the Japanese Society of Hair Restoration Surgery in Tokyo on June 25, 1995. Dr. Patrick Frechet of France was the keynote speaker. There were discussions on hair cloning and the NIDO Corporation presented three papers claiming that 90,000 artificial hair cases had been done from 70 clinics over the previous 20 years with no serious complications. The main problem was the lack of permanence, with somewhere between 15-30\% of the fibres needing to be replaced each year.

The Surgical Assistant's Corner was a new feature in the Forum, with Helen Marzola, RN of Adelaide, Australia, its first editor.

The last issue of the year (Vol. 5, No. 6; NovemberDecember 1995) was O'Tar Norwood's last edition of the Forum after a marathon six years at the helm. He generously donated the journal to the ISHRS, and, in return, the Board agreed to set up a $\$ 50,000$ Hair Transplant Foundation dedicated to education and research in hair transplant surgery.

This author (RS) took over with a promise to publish profiles on the men who had contributed so much to hair restoration surgery in the past, particularly our Japanese pioneers, about whom almost nothing was currently known. (Note: While this took many years, it was achieved in 2004.) Also pointed out were two of the costly

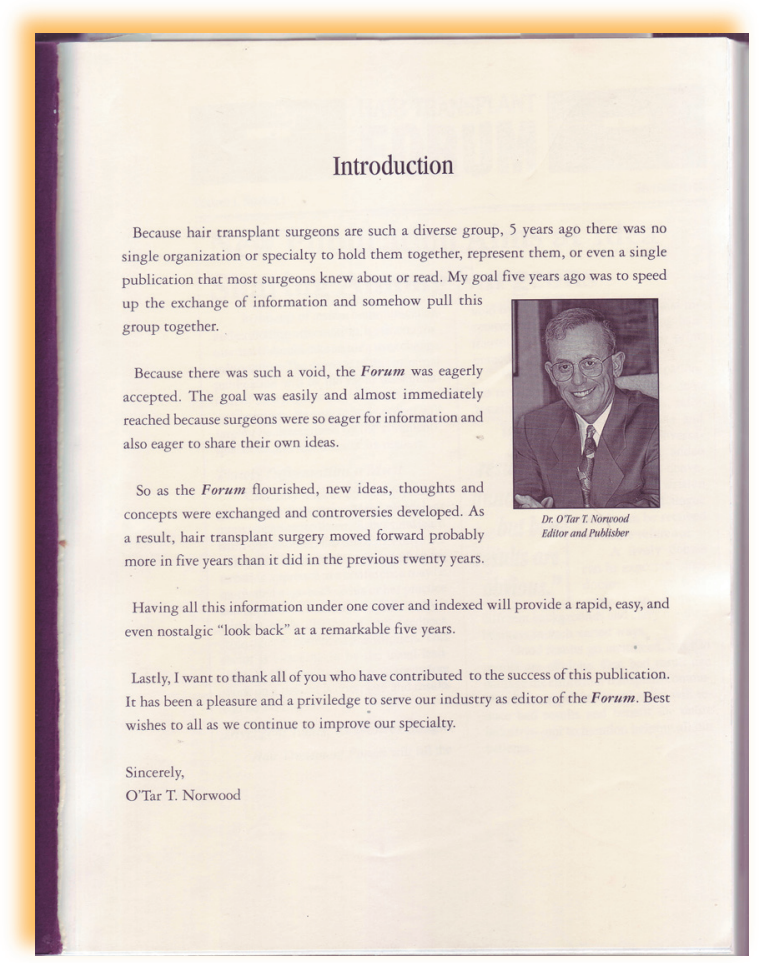

sequelae to the surgeon of small graft work: 1) that the results were often so good that patients did not bother to return for "top-up" sessions, and 2) because the results were virtually undetectable, they had little "advertising value" with the public, as did the old, larger plug grafts.

Dr. Rassman responded to requests for information into his use of megasessions. He said that he was not surprised that there were problems for many of those attempting to replicate his methods as there was "a vast array of details and tiny nuances in technique which may not be evident to the transplant surgeon accustomed to traditional techniques." Meticulous care was required in the preparation and handling of the tiny grafts, with avoidance of trauma, warming, and desiccation. This was not easy to achieve with the large team of surgical assistants working to complete the procedure in a reasonable time. He emphasized that it was important to keep graft and recipient slit extremely small, noting that "we have found that the pilosebaceous unit itself, represents the ideal implant size." (Note: It was still not called the "Follicular Unit").

A well-written and superbly illustrated article from Australian Dr. Mario Marzola offered valuable points on The Aesthetic Value of Hair.

Dr. Walter Unger made the important point that although hair counts were essential in the scientific assessment of hair transplant techniques "they aren't necessarily scientifically valid." His reasons:

1. They must be based on a reasonable number of cases. (ONE case is NOT a reasonable number.)

2. Whatever method is used, hair counting is tedious, frustrating, time-consuming, and expensive, even when assisted by photography and computers.

3. Approximately $10 \%$ of hairs in a graft will be in telogen phase when planted. These may spring to life within 3-6 months. This may be particularly embarrassing when planting "single" hairs at a hairline, as it is not unusual for two or three to grow.

4. Photographic methods for assessment of "before \& after" results must be carefully standardized with the same angle, distance, and lighting. 